\title{
Association Between Serum Alarmin Levels and Disease-specific Indices in Patients With Anti-neutrophil Cytoplasmic Antibody-associated Vasculitis
}

\author{
SUNG SOO AHN ${ }^{1 *}$, TAEJUN YOON ${ }^{2 *}$, JASON JUNGSIK SONG $^{1,3}$, YONG-BEOM PARK $^{1,3}$ and SANG-WON LEE ${ }^{1,3}$ \\ ${ }^{1}$ Division of Rheumatology, Department of Internal Medicine, \\ Yonsei University College of Medicine, Seoul, Republic of Korea; \\ ${ }^{2}$ Department of Medical Science, BK21 Plus Project, \\ Yonsei University College of Medicine, Seoul, Republic of Korea; \\ ${ }^{3}$ Institute for Immunology and Immunological Diseases, \\ Yonsei University College of Medicine, Seoul, Republic of Korea
}

\begin{abstract}
Background/Aim: We evaluated the relationship between serum alarmin levels and disease-specific indices in patients with anti-neutrophil cytoplasmic antibody (ANCA)associated vasculitis (AAV). Patients and Methods: Sera and data from 79 patients were utilized. For $A A V$-specific indices, Birmingham vasculitis activity score (BVAS), five-factor score $(F F S)$, and vasculitis damage index (VDI) were collected and serum levels of four alarmins (hepatoma-derived growth factor, high mobility group box protein 1, S100A9, and S100A12) were measured using enzyme-linked immunosorbent assay. Associations between alarmin levels, AAV-specific indices, and inflammatory laboratory markers were assessed. Results: S100A9 levels were significantly correlated with $C$ reactive protein levels $(r=0.316, p=0.005)$ and $S 100 A 12$ levels correlated with VDI $(r=0.232, p=0.040)$, which was consistent in a subgroup of patients with myeloperoxidase (perinuclear)ANCA positivity. No other associations were found between alarmin levels and BVAS, FFS, and VDI. Conclusion: The serum S100A12 level was associated with organ damage in $A A V$, especially in myeloperoxidase (perinuclear)-ANCApositive patients.
\end{abstract}

This article is freely accessible online.

*These Authors contributed equally to this study.

Correspondence to: Sang-Won Lee, MD, Ph.D., Division of Rheumatology, Department of Internal Medicine, Yonsei University College of Medicine, 50-1 Yonsei-ro, Seodaemun-gu, Seoul, 03722, Republic of Korea. Tel: +82 222281987, Fax: +82 23936884, e-mail: sangwonlee@yuhs.ac

Key Words: Anti-neutrophil cytoplasmic antibody-associated vasculitis, alarmins, damage, biomarker, S100A12.
Alarmins, often used interchangeably with the term 'damageassociated molecular patterns' are defined as an endogenous group of molecules that are released due to cellular injury or damage (1). First described as damage-associated molecular patterns in 2004 by Seong et al., alarmins are expressed constitutively in various cells and are thought to play a critical role in cellular regeneration and remodeling (2). Alarmins may also act as potent mediators of inflammation by promoting chemotaxis and inducing the expression of proteins implicated in immune activation when they are secreted extracellularly (3). Mechanistically, secreted alarmins bind to pattern recognition receptors, i.e. Toll-like receptors and receptors for advanced glycation end-products, to elicit their physiological effects. Dysregulation of this signaling can trigger aberrant immune responses $(4,5)$. Previous studies have indicated that among the alarmins, hepatoma-derived growth factor (HDGF), high mobility group box protein 1 (HMGB1), and S100 proteins can play important roles in autoimmunity (6-8).

Anti-neutrophil cytoplasmic antibody (ANCA)-associated vasculitis (AAV) is a rare multisystem autoimmune condition that belongs to a group of primary systemic vasculitides. A typical pathological feature of AAV is the presence of necrotizing inflammation in small-sized vessels, such as intraparenchymal arteries, arterioles, capillaries, and venules, and various organ involvement may be present in AAV (9). AAV comprises three distinct diseases: Microscopic polyangiitis, granulomatosis with polyangiitis, and eosinophilic granulomatosis with polyangiitis. These diseases can be differentiated according to their clinicopathological and laboratory findings of ANCA serology. As mentioned above, based on the crucial role of alarmins in the immune system, several previous studies have demonstrated that the serum level of alarmin is associated with disease-specific 
measures in inflammatory disorders. The serum level of HMGB1 has been found to be relevant to disease activity indices of ankylosing spondylitis, psoriasis, and systemic lupus erythematosus (10-12). In addition, S100 protein concentration in serum has also been proposed as a biomarker for indicating inflammation in systemic autoimmune diseases, and it is unaffected by age and sex (13). Similar to other inflammatory disorders, alteration of immunity is considered to be responsible for triggering inflammation in AAV, these studies emphasize the fact that the expression of alarmin in serum may have clinical implications in AAV. However, only limited studies investigating the association of alarmin levels with disease-specific indices in patients with AAV have been conducted. Therefore, the present study aimed to assess the serum level of alarmin in patients with AAV and its correlation with disease-specific indices.

\section{Patients and Methods}

Patient inclusion. We utilized serum samples and data from 79 patients who were included in the Severance Hospital ANCAassociated VasculitidEs (SHAVE) cohort, which is an observational registry of patients with AAV established at Severance Hospital, Republic of Korea (14). Patients were classified into AAV subtypes according to the 2007 European Medicines Agency algorithm (15) and the 2012 revised International Chapel Hill Consensus Conference Nomenclature of Vasculitides (16). The blood samples of patients enrolled in the SHAVE cohort were collected every 3 to 6 months after obtaining written informed consent. The samples were then immediately isolated and stored at $-80^{\circ} \mathrm{C}$ until further use. On the date of blood collection, the patients underwent routine laboratory tests, and AAV-specific indices [Birmingham vasculitis activity score (BVAS; version 3) (17), five-factor score (FFS) (2009) (18), and vasculitis damage index (VDI) (19)] were assessed by the attending physician. Moreover, patients with serious infections, malignancies, or secondary vasculitis other than AAV, as described in the entry criteria of the 2007 European Medicines Agency algorithm, were excluded. Informed consent was provided by all patients during the initial blood collection, and the study procedures were carried out according to the procedures specified by the Institutional Review Board of Severance Hospital (4-2016-0901).

Data collection and measurement of serum alarmins. The collected data consisted of clinical and laboratory variables, such as demographic data, AAV-specific indices, ANCA serology, disease subtypes, organ involvement, and inflammatory laboratory markers, which were obtained during serum collection. For clinical variables, demographic data comprising age, disease duration, sex, and treatment with immunosuppressive drugs (glucocorticoid, cyclophosphamide, rituximab, methotrexate, azathioprine, tacrolimus, and mycophenolate mofetil) were assessed as well as AAV-specific indices BVAS version 3, FFS, and VDI. Patterns of organ involvement were searched and distributed according to the subcategories of BVAS. Disease duration after the initial diagnosis was categorized into three different groups: i) $\leq 1$ Month, ii) 1 month to 2 years, and iii) $<2$ years.

Laboratory data investigated included ANCA serology, which was evaluated according to the detection of myeloperoxidase or perinuclear (P)-ANCA and proteinase 3 or cytoplasmic (C)-ANCA
Table I. Baseline data of the study patients $(n=79)$

\begin{tabular}{|c|c|c|}
\hline & & Value \\
\hline \multicolumn{3}{|l|}{ Demographic data } \\
\hline Age, years & Mean \pm SD & $60.4 \pm 14.6$ \\
\hline Disease duration, months & Mean \pm SD & $18.7 \pm 37.7$ \\
\hline Gender, n (\%) & Female & $46(58.2)$ \\
\hline $\begin{array}{l}\text { Immunosuppressive drug } \\
\text { treatment, } \mathrm{n}(\%)\end{array}$ & Yes & $68(86.1)$ \\
\hline \multirow{3}{*}{$\begin{array}{l}\text { AAV-specific indices, } \\
\text { mean } \pm \text { SD }\end{array}$} & BVAS & $9.7 \pm 7.5$ \\
\hline & FFS & $1.4 \pm 1.0$ \\
\hline & VDI & $3.1 \pm 1.8$ \\
\hline \multirow[t]{3}{*}{ Disease subtypes, n (\%) } & MPA & $40(50.6)$ \\
\hline & GPA & $25(31.6)$ \\
\hline & EGPA & $14(17.7)$ \\
\hline \multirow{9}{*}{$\begin{array}{l}\text { Organ involvement pattern, } \\
\mathrm{n}(\%)\end{array}$} & General & $28(35.4)$ \\
\hline & Cutaneous & $8(10.1)$ \\
\hline & Mucous/eye & $3(3.8)$ \\
\hline & ENT & $33(41.8)$ \\
\hline & Pulmonary & $46(58.2)$ \\
\hline & Cardiovascular & $3(3.8)$ \\
\hline & Abdominal & $1(1.3)$ \\
\hline & Renal & $43(54.4)$ \\
\hline & Nervous & $21(26.6)$ \\
\hline \multicolumn{3}{|l|}{ ANCA serology, n (\%) } \\
\hline & P-ANCA-positive & $50(63.3)$ \\
\hline & C-ANCA-positive & $9(11.4)$ \\
\hline & ANCA-negative & $22(27.8)$ \\
\hline \multirow[t]{3}{*}{$\begin{array}{l}\text { Inflammatory markers, } \\
\text { mean } \pm \mathrm{SD}\end{array}$} & $\begin{array}{l}\text { WBC count, } \\
\mathrm{n} / \mathrm{mm}^{3}\end{array}$ & $8,603.5 \pm 4,255.2$ \\
\hline & $\mathrm{ESR}, \mathrm{mm} / \mathrm{h}$ & $42.8 \pm 36.1$ \\
\hline & CRP, mg/l & $20.8 \pm 41.6$ \\
\hline \multicolumn{3}{|l|}{ Serum alarmins } \\
\hline HDGF, ng/ml & Mean \pm SD & $2.5 \pm 0.6$ \\
\hline $\mathrm{HMGB} 1, \mathrm{ng} / \mathrm{ml}$ & $\operatorname{Mean} \pm \mathrm{SD}$ & $0.4 \pm 0.5$ \\
\hline HMGB $1, \mathrm{n}(\%)$ & Positive & $42(53.2)$ \\
\hline $\mathrm{S} 100 \mathrm{~A} 9, \mathrm{pg} / \mathrm{ml}$ & Mean \pm SD & $2,543.0 \pm 3,638.6$ \\
\hline $\mathrm{S} 100 \mathrm{~A} 12, \mathrm{ng} / \mathrm{ml}$ & Mean \pm SD & $129.4 \pm 121.9$ \\
\hline
\end{tabular}

AAV: Anti-neutrophil cytoplasmic antibody (ANCA)-associated vasculitis; BVAS: Birmingham vasculitis activity score; $\mathrm{C}$ : cytoplasmic (proteinase 3); ESR: erythrocyte sedimentation rate; CRP: C-reactive protein; EGPA: eosinophilic granulomatosis with polyangiitis; ENT: ear, nose, and throat; FFS: five-factor score; GPA: granulomatosis with polyangiitis; HDGF: hepatoma-derived growth factor; HMGB1: high mobility group box protein 1; MPA: microscopic polyangiitis; P: perinuclear (myeloperoxidase); VDI: vasculitis damage index; WBC: white blood cell.

(20). Inflammatory markers assessed included white blood cell count, erythrocyte sedimentation rate, and C-reactive protein level. HDGF and HMGB1 levels were measured using enzyme-linked immunosorbent assay kits (Cloud-Clone Corp, Katy, TX, USA and Arigo Biolaboratories Corp., Hsinchu City, Taiwan, respectively), while S100A9 and S100A12 levels were analyzed using Human Magnetic Luminex ${ }^{\circledR}$ assay (R\&D Systems, Minneapolis, MN, USA).

Statistical analysis. All statistical analyses were performed using SPSS software (version 25 for Windows; IBM Corp., Armonk, NY, USA). Continuous variables are expressed as the mean \pm standard deviation and categorical variables as numbers with percentages. 
Table II. Associations of levels of alarmins with disease-specific indices, and levels of inflammatory markers. All data are presented as correlation coefficients with p-values in parentheses.

\begin{tabular}{|c|c|c|c|c|c|c|c|c|}
\hline & \multicolumn{4}{|c|}{ Total patients $(\mathrm{n}=79)$} & \multicolumn{4}{|c|}{ P-ANCA-positive patients $(\mathrm{n}=50)$} \\
\hline & HDGF & HMGB1 & S100A9 & S100A12 & HDGF & HMGB1 & S100A9 & S100A12 \\
\hline BVAS & $0.059(0.604)$ & $-0.019(0.865)$ & $-0.183(0.106)$ & $-0.111(0.328)$ & $0.090(0.536)$ & $-0.031(0.829)$ & $-0.142(0.325)$ & $-0.129(0.373)$ \\
\hline FFS & $0.027(0.816)$ & $-0.210(0.064)$ & $-0.080(0.485)$ & $0.003(0.977)$ & $-0.006(0.965)$ & $-0.276(0.053)$ & $-0.194(0.177)$ & $-0.062(0.670)$ \\
\hline VDI & $0.082(0.475)$ & $-0.200(0.077)$ & $-0.057(0.619)$ & $0.232(0.040)$ & $0.131(0.364)$ & $-0.253(0.076)$ & $-0.145(0.316)$ & $0.308(0.030)$ \\
\hline $\begin{array}{l}\text { WBC } \\
\text { count }\end{array}$ & $-0.035(0.757)$ & $0.096(0.400)$ & $0.120(0.292)$ & $0.086(0.450)$ & $0.086(0.553)$ & $0.077(0.595)$ & $0.256(0.073)$ & $0.142(0.326)$ \\
\hline ESR & $0.091(0.428)$ & $0.035(0.758)$ & $0.160(0.160)$ & $-0.033(0.772)$ & $0.088(0.546)$ & $0.153(0.289)$ & $0.270(0.058)$ & $-0.025(0.864)$ \\
\hline CRP & $0.096(0.399)$ & $0.146(0.200)$ & $0.316(0.005)$ & $0.118(0.300)$ & $0.182(0.207)$ & $0.203(0.158)$ & $0.477(<0.001)$ & $0.183(0.204)$ \\
\hline
\end{tabular}

ANCA: Anti-neutrophil cytoplasmic antibody; BVAS: Birmingham vasculitis activity score; CRP: C-reactive protein; ESR: erythrocyte sedimentation rate; FFS: five-factor score; HDGF: hepatoma-derived growth factor; HMGB1: high mobility group box protein 1; MPO: myeloperoxidase; P: perinuclear (myeloperoxidase); VDI: vasculitis damage index; WBC: white blood cell.

Correlations between the continuous variables were evaluated using Pearson correlation analysis, whereas the correlation coefficient between HMGB1 and continuous variables was calculated using Spearman's rho, as HMGB1 was not detectable in 37 patients. The differences between continuous variables were estimated using Student's $t$-test and analysis of variance, as appropriate. Two-tailed $p$-values of less than 0.05 were considered statistically significant.

\section{Results}

Baseline patient data. The characteristics of the 79 patients included in the study are described in Table I. The mean age and disease duration of the patients were 60.4 years, and 18.7 months, respectively. A total of 46 patients $(58.2 \%)$ were female, and $68(86.1 \%)$ were on immunosuppressive drug treatment. The mean BVAS, FFS, and VDI were 9.7, 1.4, and 3.1 , respectively. In addition, microscopic polyangiitis $(50.6 \%)$ was the most frequent diagnosis, most frequently with pulmonary manifestation (58.2) observed. P-ANCA positivity was observed in $50(63.3 \%)$ patients. The mean serum levels of HDGF, HMGB1, S100A9, and S100A12 were found to be $2.5,0.4,2.5$, and $129.4 \mathrm{ng} / \mathrm{ml}$, respectively.

Correlations among alarmin levels, $A A V$-specific indices, and levels of inflammatory markers. On assessing the relationship of alarmin levels with AAV-specific indices and inflammatory marker levels, S100A9 level was found to be significantly positively correlated with that of C-reactive protein (CRP; $\mathrm{r}=0.316, p=0.005)$, and S100A12 level was significantly positively associated with VDI $(r=0.232, p=0.040)$. This association was consistent and the correlation coefficient was numerically high in a subgroup of patients with P-ANCA positivity (S100A9 and CRP r=0.477, $p<0.001$; S100A12 and VDI, $\mathrm{r}=0.308, p=0.030$ ). No other associations were found regarding alarmins and the remaining variables evaluated (Table II).
Comparison of serum S100A12 levels according to disease subtype, ANCA serology, and organ involvement. Apart from the association between serum S100A12 level and VDI, there was no association between alarmin levels and disease-specific indices. Hence, we compared whether there were differences in serum S100A12 levels among the AAV subtypes and according to ANCA serology. However, no difference was observed in the level of serum S100A12 according to disease subtypes and the presence of ANCAs (Figure 1). Moreover, serum S100A12 levels were found to be comparable regardless of the pattern of organ involvement (Figure 2). Similarly, no difference was noted in the levels of HDGF, HMGB1, and S100A9 based on disease subtypes, ANCA serology, or organ involvement.

Difference in alarmin levels based on disease duration and treatment status. Next, we analyzed the levels of the four different alarmins according to disease duration and treatment status. When the patients were divided according to disease duration of $\leq 1$ month, 1 month to 2 years, and $>2$ years, 40, 21, and 18 patients were included in the corresponding groups, respectively. There was no statistical difference in the levels of alarmins according to disease duration and treatment status (Figures 3 and 4).

\section{Discussion}

Recently, studies have identified that alarmins can act as potential danger signals in the human body and may induce autoimmunity or perpetuate chronic inflammation in systemic autoimmune diseases. Therefore, this study was conducted to evaluate whether the level of serum alarmins might be utilized as disease-specific biomarkers in patients with AAV. Our data revealed that the serum S100A9 level was correlated with CRP level, and S100A12 level was correlated with VDI in patients with AAV and that the 

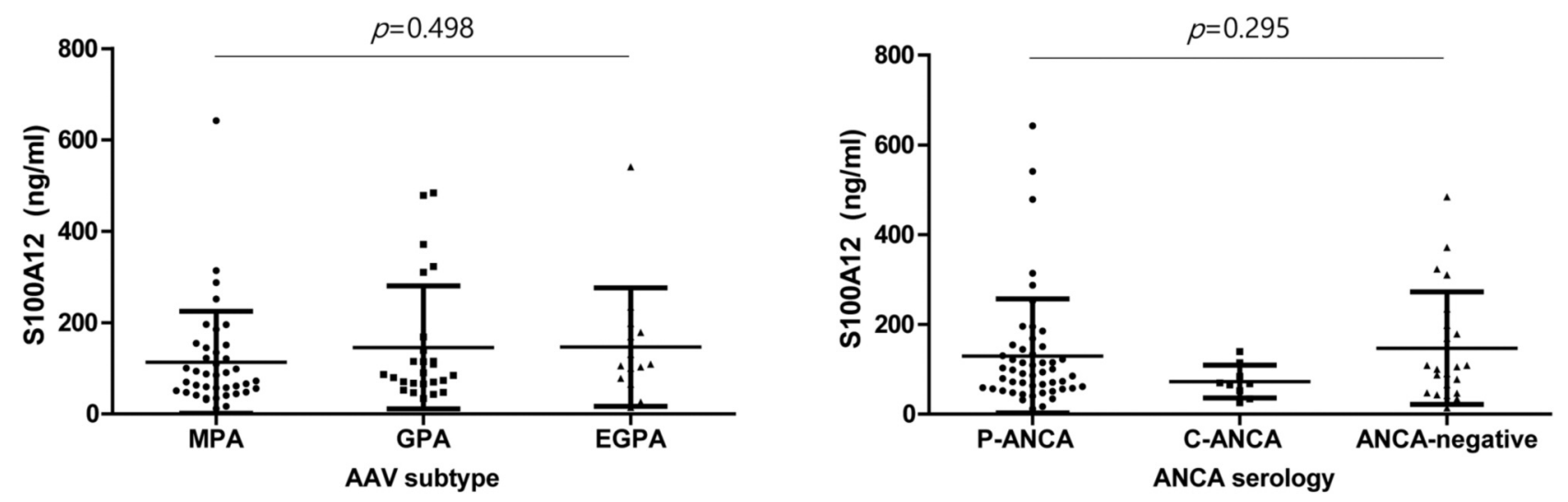

Figure 1. Serum S100A12 levels according to disease subtype and anti-neutrophil cytoplasmic antibody (ANCA) serology. Serum S100A12 level did not differ according to ANCA-associated vasculitis (AAV) subtype or ANCA serology. Lines and bars indicate the mean \pm standard deviation. C: Cytoplasmic (proteinase 3); EGPA: eosinophilic granulomatosis with polyangiitis; GPA: granulomatosis with polyangiitis; MPA: microscopic polyangiitis; P: perinuclear (myeloperoxidase).
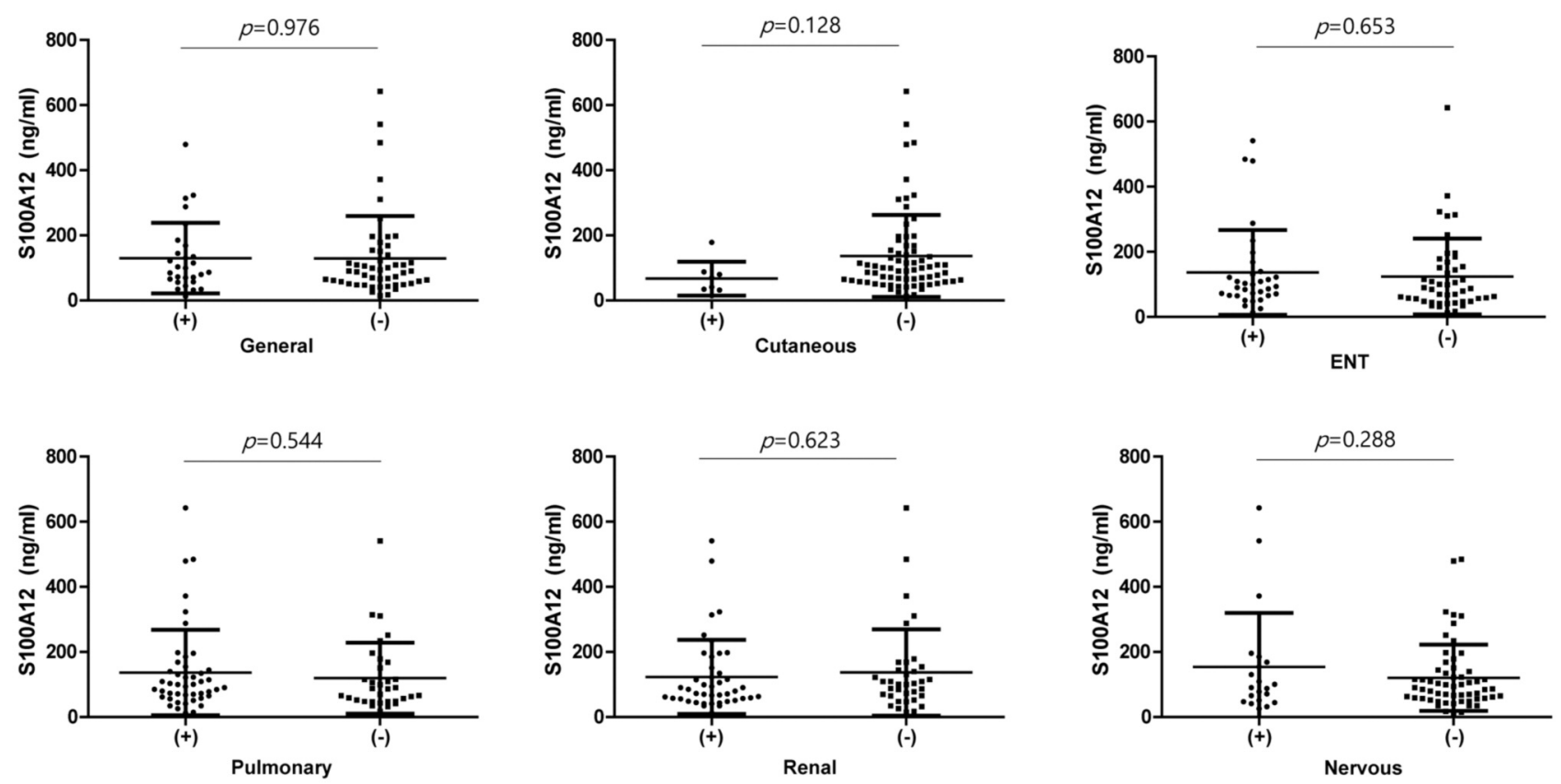

Figure 2. Comparison of serum S100A12 levels based on the pattern of organ involvement. No difference of serum S100A12 level was found regarding the presence and absence of general, cutaneous, ear, nose, and throat (ENT), pulmonary, renal, or nervous manifestation of anti-neutrophil cytoplasmic antibody-associated vasculitis. Lines and bars indicate the mean \pm standard deviation.

correlation coefficient was markedly higher in AAV patients with P-ANCA positivity, but no other associations were found. Furthermore, serum alarmin levels were not affected by other factors such as disease subtypes, ANCA serology, organ involvement, disease duration, or treatment status.

Alarmins primarily participate in immune response by modulating the activation and recruitment of immune cell subsets involved in the innate immune system, such as neutrophils and macrophages (3). Although the dysregulation of both the innate and adaptive immune systems is broadly observed and is thought to play a crucial role in AAV pathogenesis, neutrophils are traditionally regarded as major effector cells at the initial stage of AAV development (21, 22). Upon inflammatory stimuli, neutrophils are primed and 

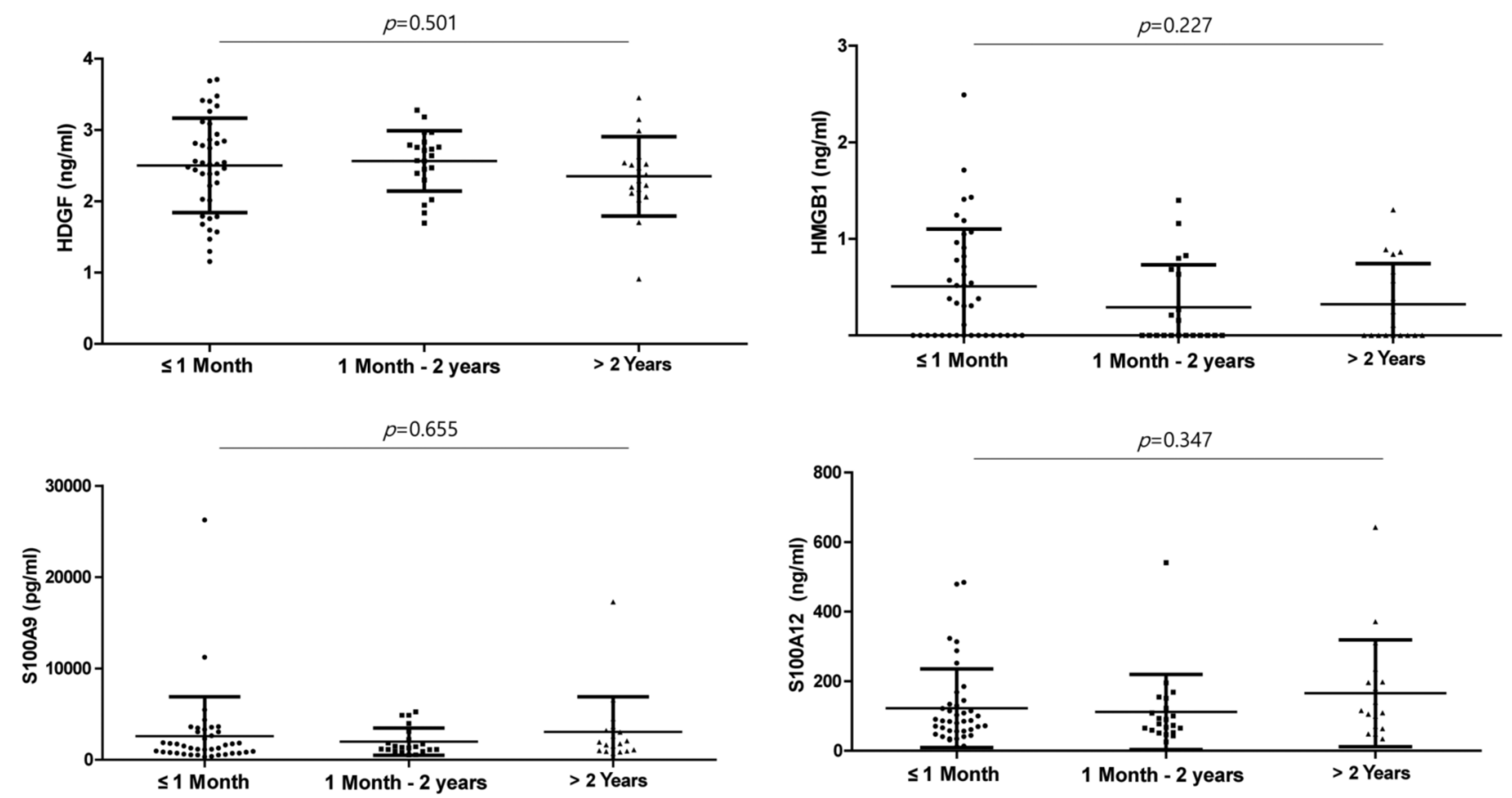

Figure 3. Alarmin levels according to disease duration. Patients were divided into three groups according to the duration of vasculitis $(\leq 1$ month, 1 month to 2 years, and $>2$ years) and the levels of alarmins were compared. No difference was noted in the levels of the four different alarmins evaluated. Lines and bars indicate the mean \pm standard deviation. HGF: Hepatoma-derived growth factor; HMGB1: high mobility group box protein 1 .

activated by ANCAs, which are responsible for the induction and maintenance of vascular inflammation (23). Interestingly, ANCAs also induce the release of neutrophil extracellular traps (NETs), which are now increasingly recognized to play an essential pathogenic role in AAV (21). NETs are composed of DNA and various proteins, including alarmins $(3,24)$, which may, in turn, lead to ANCA production and facilitate endothelial injury. In addition, NETs can be formed even in the absence of ANCAs $(25,26)$. Based on these findings, we hypothesized that the levels of serum alarmins may reflect disease-specific indices of AAV.

Unexpectedly, no significant association was found between serum HMGB1 level and disease-specific indices of AAV in this study. Previously, several studies, which evaluated the role of circulating HMGB1 levels in the blood of patients with AAV and other forms of vasculitis, reported discordant results. A study by Wang et al. reported that the plasma HMGB1 level might reflect BVAS and renal involvement in patients with AAV (27). In line with this finding, another study reported that serum HMGB1 levels were higher in patients with systemic vasculitis than in healthy controls, and they were associated with BVAS and renal involvement (28), which differs from the results of the present study. Our data are consistent with the observations made by Souza et al., who reported that the serum HMGB1 level is not a useful biomarker in AAV; in addition, a similar result was found in patients with Behçet's disease $(29,30)$.

Regarding serum S100A8/A9 levels in AAV, it was reported that changes in S100A8/A9 levels were associated with disease relapse in patients with C-ANCA positivity, and the changes were relevant to disease relapse and a gradual decrease in kidney function in patients with AAV $(31,32)$. Meanwhile, Pepper et al. reported that S100A8/A9 expression was higher in renal biopsy tissues, which increased after the cessation of treatment. S100A8/A9 expression was also higher in patients who would experience a future relapse, suggesting that S100A8/A9 level may be a potential biomarker in AAV (33). Even though a prognostic potential has been suggested through previous studies, it was not clearly indicated whether serum S100A8/9 is correlated with disease-specific indices of AAV. Our data show that serum S100A9 levels were associated with those of CRP, particularly in P-ANCA-positive patients, suggesting at least a partial relationship between serum S100A9 level and high disease burden in AAV. Since it is inconclusive whether the S100A9 level is associated with AAV-specific indices, the role of S100A8/A9 in AAV should be investigated in-depth by future studies.

Komatsuda et al. demonstrated that the serum S100A12 level was associated with BVAS and clinical and laboratory 

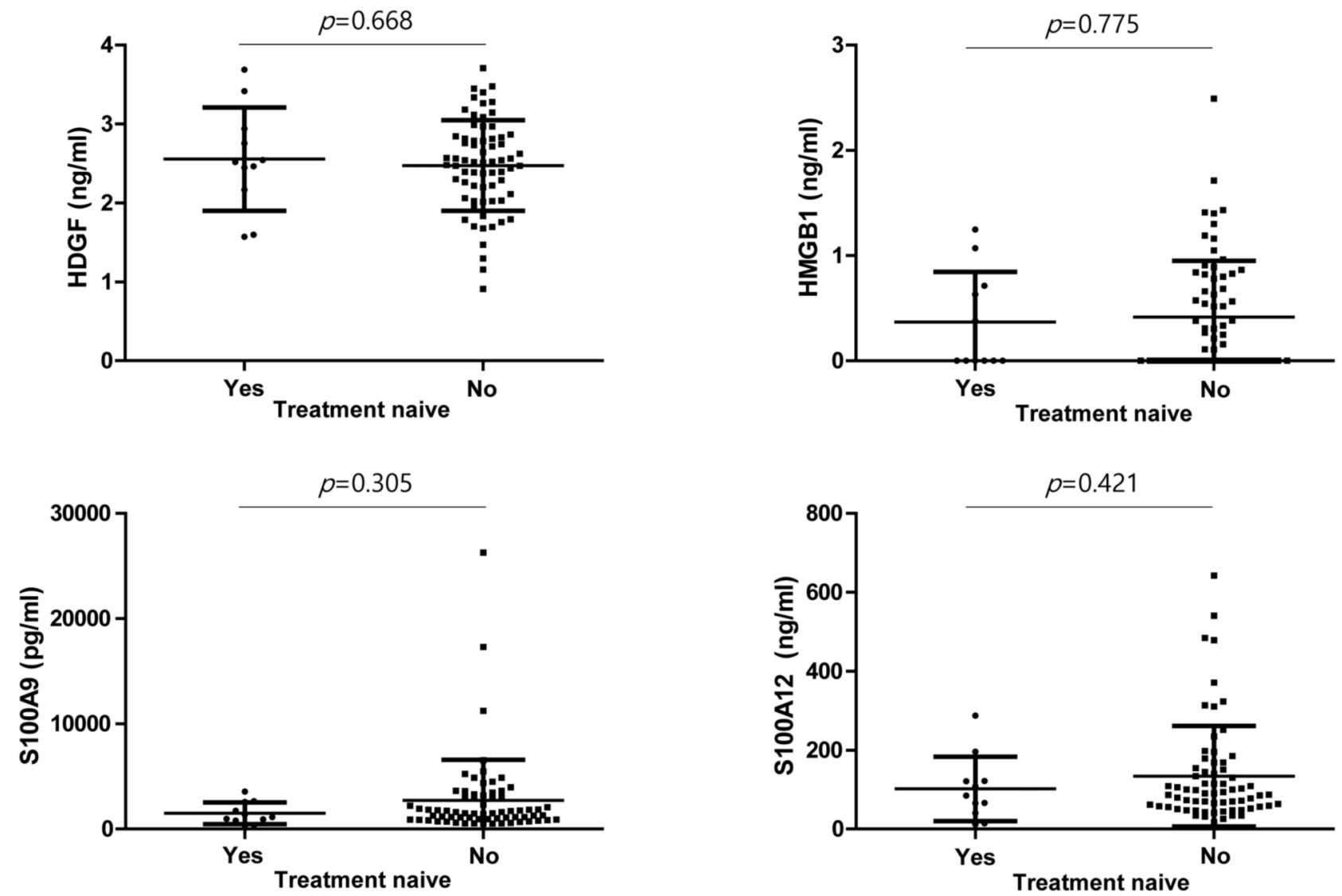

Figure 4. Alarmin levels according to immunosuppressive drug treatment status. There was no significant difference in serum level of alarmins according to treatment status. Lines and bars indicate the mean \pm standard deviation. HDGF: Hepatoma-derived growth factor; HMGB1: high mobility group box protein 1 .

parameters in 46 patients with P-ANCA-associated glomerulonephritis (34). In contrast, Brown et al. suggested the serum S100A12 level to be elevated in patients with childhood systemic vasculitis, particularly in those positive for C-ANCA (35). In the present study, we only found an association between serum S100A12 level and VDI. However, similar to the study conducted by Komatsuda et al., which showed a specific association with subgroups of AAV, we found the correlation efficient of serum S100A12 levels and VDI was higher in a subset of patients with P-ANCA positivity $(r=0.308)$. The precise cause of the discrepant results compared to the previous study is unclear. However, it is possible that the clinical implications of S100A12 in AAV vary according to the disease evaluated, ethnicity, or even geographic region, which should be explored further. Alternatively, consistent with the fact that alarmin levels are increased following injury or damage, it is also possible that the S100A12 level is increased because of increased organ damage (VDI) in AAV and this might be a biomarker indicating organ damage accrual in AAV. Nevertheless, the correlation coefficient $(r=0.232)$ was low and various factors of aging, disease course, and the sequelae of treatment may have also influenced the VDI of the patients (36). Therefore, it is unclear whether the serum S100A12 level might serve as a serological marker reflecting organ injury in $\mathrm{AAV}$, and further studies to validate our data are warranted.

Our study has several limitations. Firstly, the number of patients included in this study was relatively small. Secondly, a direct relationship between S100A12 level and VDI was not found through the results of this study. Thirdly, the associations between alarmins and disease-specific indices were evaluated cross-sectionally, and serial tests of alarmins to examine their dynamics were not performed. Therefore, we believe that additional research is necessary to improve our understanding of the role of alarmins in AAV.

In conclusion, among the four alarmins investigated, we found that the serum S100A12 level was associated with VDI in patients with AAV, and this association was pronounced in a subset of patients with P-ANCA positivity. Further investigations are necessary to provide comprehensive insights into the role of alarmins in AAV. 


\section{Conflicts of Interest}

The Authors report no conflicts of interest in regard to this study.

\section{Authors' Contributions}

Conceptualization: S.S.A. and S.W.L. Data curation: S.S.A. and T.Y. Formal analysis: S.S.A. and T.Y. Methodology: S.S.A. J.J.S. and S.W.L. Project administration: S.S.A., T.Y. and S.W.L. Supervision: J.J.S., Y.B.P. and S.W.L. Writing-original draft: S.S.A., T.Y. and S.W.L. Writing-review and editing: S.S.A., T.Y., J.J.S., Y.B.P. and S.W.L.

\section{Acknowledgements}

This research was supported by a faculty research grant of Yonsei University College of Medicine (6-2019-0184) and a grant from the Korea Health Technology R\&D Project through the Korea Health Industry Development Institute, funded by the Ministry of Health and Welfare, Republic of Korea (HI14C1324).

\section{References}

1 Chan JK, Roth J, Oppenheim JJ, Tracey KJ, Vogl T, Feldmann M, Horwood N and Nanchahal J: Alarmins: awaiting a clinical response. J Clin Invest 122(8): 2711-2719, 2012. PMID: 22850880. DOI: $10.1172 / \mathrm{JCI} 62423$

2 Seong SY and Matzinger P: Hydrophobicity: an ancient damageassociated molecular pattern that initiates innate immune responses. Nat Rev Immunol 4(6): 469-478, 2004. PMID: 15173835. DOI: $10.1038 /$ nri 1372

3 Yang, Han Z and Oppenheim JJ: Alarmins and immunity. Immunol Rev 280(1): 41-56, 2017. PMID: 29027222. DOI: 10.1111/imr.12577

4 Takeuchi $\mathrm{O}$ and Akira S: Pattern recognition receptors and inflammation. Cell 140(6): 805-820, 2010. PMID: 20303872. DOI: $10.1016 /$ j.cell.2010.01.022

5 Nie Y, Yang D and Oppenheim JJ: Alarmins and Antitumor Immunity. Clin Ther 38(5): 1042-53, 2016. PMID: 27101817. DOI: $10.1016 /$ j.clinthera.2016.03.021

6 Giri K, Pabelick CM, Mukherjee P and Prakash YS: Hepatoma derived growth factor (HDGF) dynamics in ovarian cancer cells. Apoptosis 21(3): 329-339, 2016. PMID: 26612514. DOI: 10.1007/s10495-015-1200-7

7 Bertheloot D and Latz E: HMGB1, IL-1 $\alpha$, IL-33 and S100 proteins: dual-function alarmins. Cell Mol Immunol 14(1): 4364, 2017. PMID: 27569562. DOI: 10.1038/cmi.2016.34

8 Austermann J, Spiekermann C and Roth J: S100 proteins in rheumatic diseases. Nat Rev Rheumatol 14(9): 528-541, 2018. PMID: 30076385. DOI: 10.1038/s41584-018-0058-9

9 Kitching AR, Anders HJ, Basu N, Brouwer E, Gordon J, Jayne DR, Kullman J, Lyons PA, Merkel PA, Savage COS, Specks U and Kain R: ANCA-associated vasculitis. Nat Rev Dis Primers 6(1): 71, 2020. PMID: 32855422. DOI: 10.1038/s41572-0200204-y

10 Wang C, Miao Y, Wu X, Huang Y, Sun M, Zhu Y, Zheng F, Sun $\mathrm{W}$ and Dong L: Serum HMGB1 serves as a novel laboratory indicator reflecting disease activity and treatment response in Ankylosing Spondylitis patients. J Immunol Res 2016: 6537248, 2016. PMID: 27800496. DOI: $10.1155 / 2016 / 6537248$
11 Chen T, Guo ZP, Li L, Wang L, Jia RZ, Cao N, Qin S and Li MM: Increased HMGB1 serum levels and altered HMGB1 expression in patients with psoriasis vulgaris. Arch Dermatol Res 305(3): 263-267, 2013. PMID: 23440398. DOI: 10.1007/ s00403-013-1330-0

12 Abdulahad DA, Westra J, Bijzet J, Limburg PC, Kallenberg CG and Bijl M: High mobility group box 1 (HMGB1) and antiHMGB1 antibodies and their relation to disease characteristics in systemic lupus erythematosus. Arthritis Res Ther 13(3): R71, 2011. PMID: 21548924. DOI: 10.1186/ar3332

13 Holzinger D, Tenbrock K and Roth J: Alarmins of the S100family in juvenile autoimmune and auto-inflammatory diseases. Front Immunol 10: 182, 2019. PMID: 30828327. DOI: 10.3389/ fimmu.2019.00182

14 Ahn S, Yoon T, Song J, Park Y and Lee S: Lipid Profiles in Antineutrophil Cytoplasmic Antibody-associated Vasculitis: A Crosssectional analysis. Journal of Rheumatic Diseases 27(4): 261269, 2020. DOI: $10.4078 /$ jrd.2020.27.4.261

15 Watts R, Lane S, Hanslik T, Hauser T, Hellmich B, Koldingsnes W, Mahr A, Segelmark M, Cohen-Tervaert JW and Scott D: Development and validation of a consensus methodology for the classification of the ANCA-associated vasculitides and polyarteritis nodosa for epidemiological studies. Ann Rheum Dis 66(2): 222-227, 2007. PMID: 16901958. DOI: 10.1136/ard. 2006.054593

16 Jennette JC, Falk RJ, Bacon PA, Basu N, Cid MC, Ferrario F, Flores-Suarez LF, Gross WL, Guillevin L, Hagen EC, Hoffman GS, Jayne DR, Kallenberg CG, Lamprecht P, Langford CA, Luqmani RA, Mahr AD, Matteson EL, Merkel PA, Ozen S, Pusey CD, Rasmussen N, Rees AJ, Scott DG, Specks U, Stone JH, Takahashi K and Watts RA: 2012 revised international chapel hill consensus conference nomenclature of vasculitides. Arthritis Rheum 65(1): 1-11, 2013. PMID: 23045170. DOI: 10.1002/art.37715

17 Mukhtyar C, Lee R, Brown D, Carruthers D, Dasgupta B, Dubey S, Flossmann O, Hall C, Hollywood J, Jayne D, Jones R, Lanyon P, Muir A, Scott D, Young L and Luqmani RA: Modification and validation of the Birmingham Vasculitis Activity Score (version 3). Ann Rheum Dis 68(12): 1827-1832, 2009. PMID: 19054820. DOI: 10.1136/ard.2008.101279

18 Guillevin L, Pagnoux C, Seror R, Mahr A, Mouthon L, Toumelin PL and French Vasculitis Study Group (FVSG).: The Five-Factor Score revisited: assessment of prognoses of systemic necrotizing vasculitides based on the French Vasculitis Study Group (FVSG) cohort. Medicine (Baltimore) 90(1): 19-27, 2011. PMID: 21200183. DOI: 10.1097/MD.0b013e318205a4c6

19 Bhamra K and Luqmani R: Damage assessment in ANCAassociated vasculitis. Curr Rheumatol Rep 14(6): 494-500, 2012. PMID: 22983618. DOI: 10.1007/s11926-012-0291-1

20 Bossuyt X, Cohen Tervaert JW, Arimura Y, Blockmans D, Flores-Suárez LF, Guillevin L, Hellmich B, Jayne D, Jennette JC, Kallenberg CGM, Moiseev S, Novikov P, Radice A, Savige JA, Sinico RA, Specks U, van Paassen P, Zhao MH, Rasmussen N, Damoiseaux J and Csernok E: Position paper: Revised 2017 international consensus on testing of ANCAs in granulomatosis with polyangiitis and microscopic polyangiitis. Nat Rev Rheumatol 13(11): 683-692, 2017. PMID: 28905856. DOI: 10.1038/nrrheum.2017.140

21 Nakazawa D, Masuda S, Tomaru U and Ishizu A: Pathogenesis and therapeutic interventions for ANCA-associated vasculitis. 
Nat Rev Rheumatol 15(2): 91-101, 2019. PMID: 30542206. DOI: $10.1038 / \mathrm{s} 41584-018-0145-\mathrm{y}$

22 Savage CO: Pathogenesis of anti-neutrophil cytoplasmic autoantibody (ANCA)-associated vasculitis. Clin Exp Immunol 164 Suppl 1: 23-26, 2011. PMID: 21447127. DOI: 10.1111/j. $1365-2249.2011 .04362 . \mathrm{x}$

23 Kronbichler A, Lee KH, Denicolò S, Choi D, Lee H, Ahn D, Kim KH, Lee JH, Kim H, Hwang M, Jung SW, Lee C, Lee H, Sung H, Lee D, Hwang J, Kim S, Hwang I, Kim DY, Kim HJ, Cho G, Cho Y, Kim D, Choi M, Park J, Park J, Tizaoui K, Li H, Smith L, Koyanagi A, Jacob L, Gauckler P and Shin JI: Immunopathogenesis of ANCA-Associated Vasculitis. Int J Mol Sci 21(19): 7319, 2020. PMID: 33023023. DOI: 10.3390/ ijms 21197319

24 Urban CF, Ermert D, Schmid M, Abu-Abed U, Goosmann C, Nacken W, Brinkmann V, Jungblut PR and Zychlinsky A: Neutrophil extracellular traps contain calprotectin, a cytosolic protein complex involved in host defense against Candida albicans. PLoS Pathog 5(10): e1000639, 2009. PMID: 19876394. DOI: 10.1371/journal.ppat.1000639

25 Delgado-Rizo V, Martínez-Guzmán MA, Iñiguez-Gutierrez L, García-Orozco A, Alvarado-Navarro A and Fafutis-Morris M: Neutrophil Extracellular Traps and Its Implications in Inflammation: An Overview. Front Immunol 8: 81, 2017. PMID: 28220120. DOI: 10.3389/fimmu.2017.00081

26 Kraaij T, Kamerling SWA, van Dam LS, Bakker JA, Bajema IM, Page T, Brunini F, Pusey CD, Toes REM, Scherer HU, Rabelink TJ, van Kooten $\mathrm{C}$ and Teng YKO: Excessive neutrophil extracellular trap formation in ANCA-associated vasculitis is independent of ANCA. Kidney Int 94(1): 139-149, 2018. PMID: 29606398. DOI: 10.1016/j.kint.2018.01.013

27 Wang C, Gou SJ, Chang DY, Yu F, Zhao MH and Chen M: Association of circulating level of high mobility group box 1 with disease activity in antineutrophil cytoplasmic autoantibodyassociated vasculitis. Arthritis Care Res (Hoboken) 65(11): 18281834, 2013. PMID: 24591411. DOI: 10.1002/acr.22187

28 Zhu B, Li N, Zhu Q, Wu T, Heizati M, Wang G, Yao X, Luo Q, Liu S, Liu S and Hong J: Association of serum high mobility group box 1 levels with disease activity and renal involvement in patients with systemic vasculitis. Medicine (Baltimore) 98(6): e14493, 2019. PMID: 30732222. DOI: 10.1097/MD.00000000 00014493

29 de Souza A, Westra J, Bijzet J, Limburg PC, Stegeman CA, Bijl $\mathrm{M}$ and Kallenberg CG: Is serum HMGB1 a biomarker in ANCAassociated vasculitis? Arthritis Res Ther 15(5): R104, 2013. PMID: 24007972. DOI: 10.1186/ar4284

30 de Souza AW, Perazzio SF, de França NR, Andrade LE, Bijl M, Westra J and Kallenberg CG: High mobility group box 1 serum levels are increased in Behçet's disease, but not associated with disease activity or disease manifestations. Rheumatology (Oxford) 54(12): 2151-2155, 2015. PMID: 26170374. DOI: $10.1093 /$ rheumatology/kev202
31 Pepper RJ, Draibe JB, Caplin B, Fervenza FC, Hoffman GS, Kallenberg CG, Langford CA, Monach PA, Seo P, Spiera R, William St Clair E, Tchao NK, Stone JH, Specks U, Merkel PA, Salama AD and RAVE-Immune Tolerance Network Research Group.: Association of serum calprotectin (S100A8/A9) level with disease relapse in Proteinase 3-antineutrophil cytoplasmic antibody-associated Vasculitis. Arthritis Rheumatol 69(1): 185193, 2017. PMID: 27428710. DOI: 10.1002/art.39814

32 Martinez Valenzuela L, Draibe J, Quero Ramos M, Fulladosa Oliveras X, Melilli E, Cruzado Garrit JM and Torras Ambrós J: Calprotectin as a smoldering activity detection tool and renal prognosis biomarker in ANCA associated vasculitis. PLoS One 13(10): e0205982, 2018. PMID: 30347000. DOI: 10.1371/ journal.pone.0205982

33 Pepper RJ, Hamour S, Chavele KM, Todd SK, Rasmussen N, Flint S, Lyons PA, Smith KG, Pusey CD, Cook HT and Salama AD: Leukocyte and serum S100A8/S100A9 expression reflects disease activity in ANCA-associated vasculitis and glomerulonephritis. Kidney Int 83(6): 1150-1158, 2013. PMID: 23423260. DOI: $10.1038 / \mathrm{ki} .2013 .2$

34 Komatsuda A, Ohtani H, Wakui H, Chyzh KA, Hatakeyama T, Iwamoto K, Maki N, Kimura T, Hitomi J and Sawada K: Increased serum levels of S100A12 in patients with MPOANCA-associated glomerulonephritis. Clin Nephrol 66(5): 315321, 2006. PMID: 17140160. DOI: 10.5414/cnp66315

35 Brown KL, Lubieniecka JM, Armaroli G, Kessel K, Gibson KM, Graham J, Liu D, Hancock REW, Ross CJ, Benseler SM, Luqmani RA, Cabral DA, Foell D and Kessel C: s100a12 serum levels and PMN counts are elevated in childhood systemic Vasculitides especially involving Proteinase 3 specific antineutrophil cytoplasmic antibodies. Front Pediatr 6: 341, 2018. PMID: 30533405. DOI: 10.3389/fped.2018.00341

36 Sada KE, Ohashi K, Asano Y, Hayashi K, Morishita M, Watanabe H, Matsumoto Y, Fujimoto S, Takasaki Y, Yamagata K, Banno S, Dobashi H, Amano K, Harigai M, Arimura Y, Makino $\mathrm{H}$ and Japan Research Committee of the Ministry of Health, Labour, and Welfare for Intractable Vasculitis (JPVAS) and the Research Committee of Intractable Renal Disease of the Ministry of Health, Labour, and Welfare of Japan.: Treatmentrelated damage in elderly-onset ANCA-associated vasculitis: safety outcome analysis of two nationwide prospective cohort studies. Arthritis Res Ther 22(1): 236, 2020. PMID: 33046139. DOI: $10.1186 / \mathrm{s} 13075-020-02341-6$
Received January 20, 2021

Revised February 10, 2021

Accepted February 11, 2021 